\title{
Commentary: Mobile and Interactive Media Use by Young Children: The Good, the Bad, and the Unknown
}

\author{
Cedric Galetzka* \\ Division of Cognitive Sciences, Psychology Department, University of Potsdam, Potsdam, Germany
}

Keywords: embodied cognition, children's development, touchscreen devices, learning, smartphones

\section{A commentary on}

Mobile and Interactive Media Use by Young Children: The Good, the Bad, and the Unknown by Radesky, J. S., Schumacher, J., and Zuckerman, B. (2015). Pediatrics 135, 1-3. doi: 10.1542/peds. 2014-2251

There seems to be a broad consensus among today's parents that early exposure to digital media is less enriching than real-life experiences (Wooldridge, 2016). While this concern may rightly apply to traditional media such as television, new interactive devices (e.g., smartphones and tablets), on the contrary, are often marketed as supplemental learning tools for children (Kirkorian et al.,

\section{OPEN ACCESS}

Edited by:

Anna M. Borghi,

Sapienza University of Rome, Italy

Reviewed by:

Loï P. Heurley,

Paris West University Nanterre La

Défense, France

*Correspondence:

Cedric Galetzka

galetzka@uni-potsdam.de

Specialty section:

This article was submitted to

Cognition,

a section of the journal

Frontiers in Psychology

Received: 13 January 2017 Accepted: 13 March 2017 Published: 28 March 2017

Citation:

Galetzka C (2017) Commentary: Mobile and Interactive Media Use by Young Children: The Good, the Bad, and the Unknown.

Front. Psychol. 8:461. doi: 10.3389/fpsyg.2017.00461
2009; Christakis, 2014; Apple, 2016). However, Radesky et al. (2015) recently pointed out that research on the impact of interactive devices on children's cognition cannot keep up with the pace of technological advances. The most recent guidelines on recommended screen time were updated before the first tablets even made their way onto the market (Christakis, 2014). Supplementing Radesky et al. (2015), this commentary aims to clarify the influence of modern touchscreen devices on children's cognitive development from the perspective of embodied cognition.

Embodied cognition highlights that the development of cognitive processes crucially depends on active interactions between one's body and the environment (Barsalou, 1999; Thelen et al., 2001). These sensorimotor interactions are thought to form the basis for many high-level processes such as object recognition and decision-making (Smith, 2005; Rivière and David, 2013). Importantly, children in early developmental stages seem to build up fewer associations from interactions when merely observing an action being executed instead of performing it (Smith, 2005). Modern interactive devices address this concern in that they allow for active bodily interactions via touchscreens (Black et al., 2012; Christakis, 2014).

Radesky et al. (2015) note that research has been sparse on whether children can actually benefit from touchscreen use. However, recent studies indicate that children can transfer acquired knowledge from touchscreen interfaces to physical objects. Wang et al. (2016) compared the effectiveness of teaching children clock reading using an iPad touchscreen app, a toy clock, or a paper drawing. The researchers found that children learned equally well from interactive media and traditional toys, with both conditions outperforming the paper drawing group. Importantly, children were able to transfer learned skills from touchscreens to physical objects. The same has been found in a study teaching children how to solve the Tower of Hanoi problem (Huber et al., 2016). In sum, the typical transfer deficit observed with traditional media seems to be absent when children are actively engaged with devices via touchscreens (Strasburger, 2015; Huber et al., 2016).

However, going beyond Radesky et al. (2015), simple swiping and tapping motions on touchscreens seem impoverished compared to the complex hand movements that facilitate 
exploration of objects (Lederman and Klatzky, 1987; Spitzer, 2013). Confirming this suspicion, Crescenzi et al. (2014) compared children's performance on a drawing task in an iPad vs. paper condition. The researchers point out that touchscreens limit the amount of fingers available for object manipulation. Moreover, qualitative aspects of touch are reduced and important haptic information, such as surface texture, are completely absent. However, the authors note that iPads allow for new types of touch, including more complex touch sequences. Interestingly, a recent study found that touchscreen use in early childhood is correlated with fine motor control (Bedford et al., 2016). Nevertheless, the authors argue that negative effects on more complex motor processes might only become apparent in later stages of development. Therefore, developers of children's applications need to take principles of embodiment, such as allowing for more complex bodily interactions, into account in order to guarantee for a healthy cognitive development (Antle, 2009).

Supporting Radesky et al. (2015), while children are engaged with interactive media, they miss out on other potentially more fruitful activities that foster an understanding around them. However, the limited types of touch of today's smartphones could provide certain beneficial learning effects by replacing traditional forms of media, such as television (Christakis, 2014). Kirkorian et al. (2016) compared the performance of children aged between 24 and 36 months on a word learning task. The children were either instructed to watch a video from a touchscreen or use touch-based gestures during video presentation. The authors observed that especially younger children benefited from contingent touchscreen interactions that accompanied taskrelevant information. Interestingly, this condition appeared to be counterproductive for the oldest children who participated in the experiment. In a follow-up study, Choi and Kirkorian (2016) argued that contingent touch-based interactions mainly facilitate learning in younger children by supporting selective attention mechanism. Future research needs to specify under which conditions contingent touchscreen responses supplement learning.

Moreover, Eisen and Lillard (2016) observed that children consistently prefer real-world objects, such as books, for learning

\section{REFERENCES}

Antle, A. N. (2009). Embodied child computer interaction: why embodiment matters. Interactions 16, 27-30. doi: 10.1145/1487632.1 487639

Apple (2016). Apps for Education. Available online at: http://www.apple.com/ education/products/\#learning-with-ipad (Accessed January 10, 2017).

Barsalou, L. W. (1999). Perceptions of perceptual symbols. Behav. Brain Sci. 22, 637-660.

Bedford, R., de Urabain, I. R. S., Cheung, C. H., Karmiloff-Smith, A., and Smith, T. J. (2016). Toddlers' fine motor milestone achievement is associated with early touchscreen scrolling. Front. Psychol. 7:1108. doi: 10.3389/fpsyg.2016.01108

Black, J. B., Segal, A., Vitale, J., and Fadjo, C. (2012). "Embodied cognition and learning environment design" in Theoretical Foundations of Learning Environments, eds D. Jonassen and S. Land (New York, NY: Routledge), $198-223$. over touchscreen devices. Importantly, children seem to grasp the interactional nature of touchscreens compared to traditional media but fail to conceive them as useful learning tools. The authors reasoned that children discount the learning value of interactive devices due to the circumstances they encounter them. Correspondingly, Radesky et al. (2014) already pointed out that parents mostly let their children use interactive media during routine tasks. Children would benefit from a more systematic approach to learning from touchscreens that takes these aspects into account. Recently, Kucirkova (2016) proposed a framework to bring developers, practitioners, and researchers together to design empirically based applications.

To sum up, the extent to which the advantages of reallife learning might be substitutable by touchscreen devices seems to be heavily context-dependent. Even in the absence of joint engagement, which was shown to greatly benefit learning according to Radesky et al. (2015), interactive media could represent useful supplementary learning tools in educational contexts (Kwok et al., 2016). In that sense, other fruitful approaches could also be to compare the effectiveness of touchscreen devices with other embodied learning approaches such as using active role-play to facilitate reading comprehension (Glenberg et al., 2004; Black et al., 2012). As with any other newly popularized technology, the true potential of smartphones is likely to be discovered along the way (Lovato and Waxman, 2016). Ultimately, insights from embodied cognition contribute to understanding how the touch in touchscreens supports the process of learning.

\section{AUTHOR CONTRIBUTIONS}

The author confirms being the sole contributor of this work and approved it for publication.

\section{ACKNOWLEDGMENTS}

I would like to thank Martin H. Fischer and Alex Miklashevsky for helpful critique and insightful comments.
Choi, K., and Kirkorian, H. L. (2016). Touch or watch to learn? Toddlers' object retrieval using contingent and noncontingent video. Psychol. Sci. 27, 726-736. doi: 10.1177/0956797616636110

Christakis, D. A. (2014). Interactive media use at younger than the age of 2 years: time to rethink the American Academy of Pediatrics guideline? JAMA Pediatr. 168, 399-400. doi: 10.1001/jamapediatrics.2013.5081

Crescenzi, L., Jewitt, C., and Price, S. (2014). The role of touch in preschool children's learning using iPad versus paper interaction. Aust. J. Lang. Literacy $37,86$.

Eisen, S., and Lillard, A. S. (2016). Young children's thinking about touchscreens versus other media in the US. J. Children Media. 1-13. doi: 10.1080/17482798.2016.1254095

Glenberg, A. M., Gutierrez, T., Levin, J. R., Japuntich, S., and Kaschak, M. P. (2004). Activity and imagined activity can enhance young children's reading comprehension. J. Educ. Psychol. 96:424. doi: 10.1037/0022-0663. 96.3.424 
Huber, B., Tarasuik, J., Antoniou, M. N., Garrett, C., Bowe, S. J., Kaufman, J., et al. (2016). Young children's transfer of learning from a touchscreen device. Comput. Human Behav. 56, 56-64. doi: 10.1016/j.chb.2015. 11.010

Kirkorian, H. L., Choi, K., and Pempek, T. A. (2016). Toddlers' word learning from contingent and noncontingent video on touch screens. Child Dev. 87, 405-413. doi: $10.1111 /$ cdev. 12508

Kirkorian, H. L., Pempek, T. A., Murphy, L. A., Schmidt, M. E., and Anderson, D. R. (2009). The impact of background television on parentchild interaction. Child Dev. 80, 1350-1359. doi: 10.1111/j.1467-8624.2009. 01337

Kucirkova, N. (2016). iRPD-A framework for guiding design-based research for iPad apps. Br. J. Educ. Technol. 48, 598-610. doi: 10.1111/bjet.12389

Kwok, K., Ghrear, S., Li, V., Haddock, T., Coleman, P., and Birch, S. A. (2016). Children can learn new facts equally well from interactive media versus face to face instruction. Front. Psychol. 7:1603. doi: 10.3389/fpsyg.20 16.01603

Lederman, S. J., and Klatzky, R. L. (1987). Hand movements: a window into haptic object recognition. Cogn. Psychol. 19, 342-368. doi: 10.1016/ 0010-0285(87)90008-9

Lovato, S. B., and Waxman, S. R. (2016). Young children learning from touch screens: taking a wider view. Front. Psychol. 7:1078. doi: 10.3389/fpsyg.2016. 01078

Radesky, J. S., Kistin, C. J., Zuckerman, B., Nitzberg, K., Gross, J., Kaplan-Sanoff, M., et al. (2014). Patterns of mobile device use by caregivers and children during meals in fast food restaurants. Pediatrics 133. doi: 10.1542/peds.2013-3703

Radesky, J. S., Schumacher, J., and Zuckerman, B. (2015). Mobile and interactive media use by young children: the good, the bad, and the unknown. Pediatrics 135, 1-3. doi: 10.1542/peds.2014-2251
Rivière, J., and David, E. (2013). Perceptual-motor constraints on decision making: the case of the manual search behavior for hidden objects in toddlers. J. Exp. Child Psychol. 115, 42-52. doi: 10.1016/j.ecp.2012.11.006

Smith, L. B. (2005). Action alters shape categories. Cogn. Sci. 29, 665-679. doi: 10.1207/s15516709cog0000_13

Spitzer, M. (2013). To swipe or not to swipe?-The question in present-day education. Trends Neurosci. Educ. 3, 95-99. doi: 10.1016/j.tine.2013.09.002

Strasburger, V. (2015). Should babies be watching and using screens? The answer is surprisingly complicated. Acta Paediatr. 104, 967-968. doi: 10.1111/apa.13105

Thelen, E., Schöner, G., Scheier, C., and Smith, L. B. (2001). The dynamics of embodiment: a field theory of infant perseverative reaching. Behav. Brain Sci. 24, 1-34. doi: 10.1017/S0140525X01003910

Wang, F., Xie, H., Wang, Y., Hao, Y., and An, J. (2016). Using touchscreen tablets to help young children learn to tell time. Front. Psychol. 7:1800. doi: 10.3389/fpsyg.2016.01800

Wooldridge, M. B. (2016). An Ecology of Technology: Infants, Toddlers, and Mobile Screen Devices, Doctoral dissertation, University of British Columbia. doi: $10.14288 / 1.0300168$

Conflict of Interest Statement: The author declares that the research was conducted in the absence of any commercial or financial relationships that could be construed as a potential conflict of interest.

Copyright (c) 2017 Galetzka. This is an open-access article distributed under the terms of the Creative Commons Attribution License (CC BY). The use, distribution or reproduction in other forums is permitted, provided the original author(s) or licensor are credited and that the original publication in this journal is cited, in accordance with accepted academic practice. No use, distribution or reproduction is permitted which does not comply with these terms. 